\title{
Unusual cause of haemorrhage from surgical wound in a child
}

\author{
Roop Singh · Sarita Magu • Virender Kumar Kadian • \\ Ramchander Siwach · Rajesh Kumar Rohilla • \\ Vishal Dhir
}

Received: 17 June 2008/Accepted: 17 February 2009/Published online: 10 March 2009

(C) Springer-Verlag 2009

\begin{abstract}
Haemorrhage from a surgical wound can be from many potential sources such as injury to vessel, muscle and bone; bleeding disorders; incomplete haemostasis; pseudoaneurysm; and neovascularisation. We report an unusual cause of haemorrhage from the surgical incision in a 9-year-old child. We emphasize that a high index of suspicion is required for early diagnosis, and pseudoaneurysm and neoangiogenesis should be considered in the differential diagnosis of soft tissue masses resulting from direct, blunt trauma even in children.
\end{abstract}

Keywords Pseudoaneurysm · Profunda femoris artery · Haemorrhage

\section{Introduction}

Pseudoaneurysms develop as a result of inflammation, trauma, neoplasm, or surgical procedures, and originate from a disruption of arterial continuity with extravasations of blood into the surrounding tissues, where a fibrous tissue capsule is formed [1-9]. Also a pseudoaneurysm may have variable amount of the media and adventitia as apart of

R. Singh $(\varangle) \cdot$ V. K. Kadian · R. Siwach · R. K. Rohilla Department of Orthopaedic Surgery, Paraplegia and Rehabilitation, Pt. B.D. Sharma PGIMS, 9-J/52, Medical Enclave, Rohtak 124001, Haryana, India e-mail: drroopsingh@rediffmail.com

\section{S. Magu}

Department of Radio Diagnosis and Imaging, Pt. B.D. Sharma PGIMS, Rohtak 124001, Haryana, India

V. Dhir

Department of Cardio-Thoracic and Vascular Surgery, Pt. B.D. Sharma PGIMS, Rohtak 124001, Haryana, India their wall. Traumatic arterial injuries can result in serious early and delayed complications, months or even years after the injury $[2,9]$.

In this case report, we present a case of pseudoaneurysm following blunt trauma to the thigh in a child with triad of swelling, bleeding and anaemia.

\section{Case report}

A 9-year-old male child was referred to our institute with haemorrhage, when a surgeon in periphery incised a posttraumatic swelling left thigh assuming it to be abscess. On admission, he had a blood pressure of $96 / 60 \mathrm{mmHg}$, pulse rate of $115 \mathrm{bpm}$ and oxygen saturation of $98 \%$. Peripheral pulses were palpable. No active bleed was present from the stitched incision site at that time (Fig. 1). He was anaemic ( $\mathrm{Hb} 4 \mathrm{~g}$ ), with normal coagulation profile (PTI/PTTK). Xray of left thigh showed soft tissue swelling and no bony pathology (Fig. 2). Ultrasonography revealed haematoma in subcutaneous tissues and in muscles planes. The patient was managed conservatively with blood transfusion and dressings of the surgical wound. The haemoglobin level rose to $8.4 \mathrm{~g} / \mathrm{dl}$ by fifth postoperative day and a repeat ultrasonography showed slight decrease in the haematoma. On tenth postoperative day, the patient had an episode of active bleed from incision site with dressing fully soaked with fresh blood. Patient was resuscitated with blood transfusion, as he was hypotensive and anaemic $(5.2 \mathrm{~g} / \mathrm{dl})$. Urgent MRI and CT angiography were done. CT angiography showed hypodense area in vasti and vessels coursing in between the hypodense area. A dilated tortuous vessel was seen beneath the incision site and fresh bleed (Fig. 3a, b). MRI showed large haematoma in vasti and subcutaneous plane (Fig. 4a, b). Patient was shifted to operation 


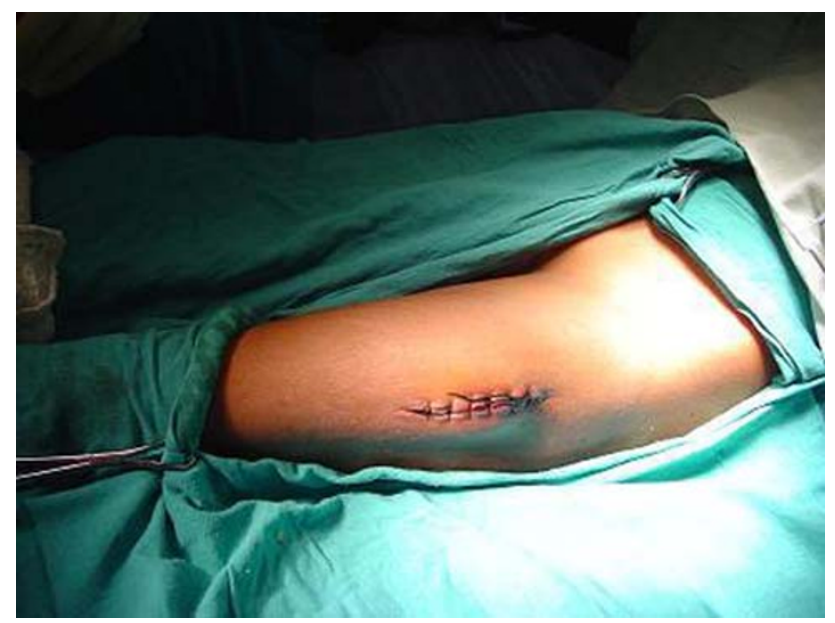

Fig. 1 Stitched surgical incision with no active bleed at the time of presentation

theatre, adequate cross-matched blood was arranged and the wound was explored. Common femoral and profunda femoris arteries were isolated and tagged to deal with any eventuality of exsanguinations during wound exploration. Wound exploration showed large haematoma in subcutaneous tissue and in plane between rectus femoris and vasti muscles. A tortuous, dilated vessel was found to be the source of bleeding and forming pseudoaneurysm (Fig. 5a). Profunda femoris and this abnormal vessel were ligated

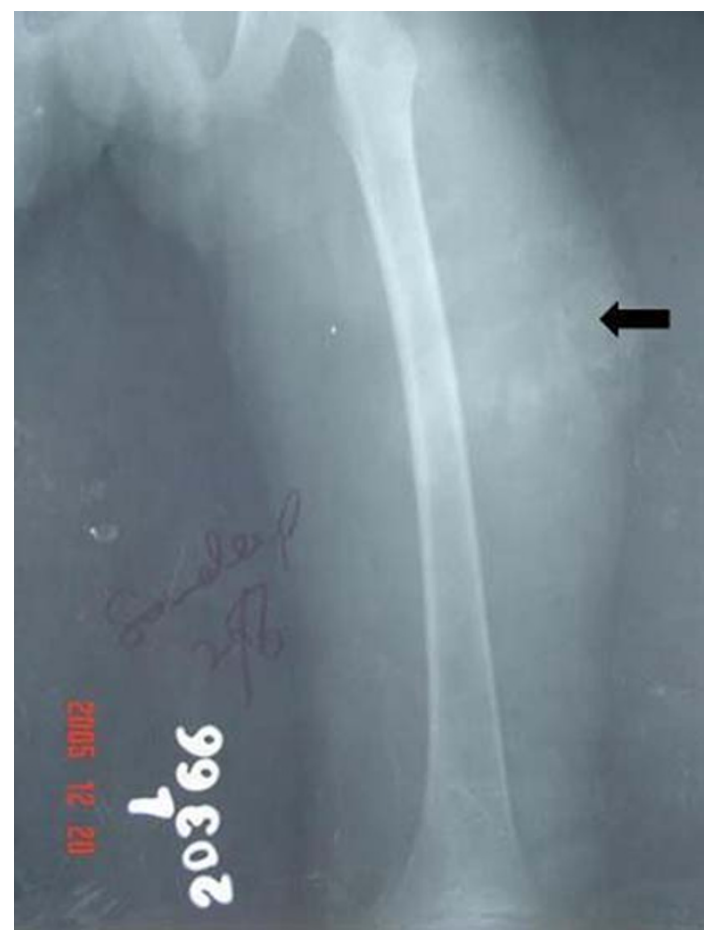

Fig. 2 Anteroposterior radiograph showing gross soft tissue swelling without any fracture (arrow)
(Fig. 5b). Postoperatively distal vessels were palpable and thigh swelling subsided in 3 weeks time. There was no bleeding or swelling until last follow-up of 2 years.

\section{Discussion}

Pseudoaneurysm of profunda femoris artery has been reported following blunt and penetrating trauma to the thigh, and operative procedures of the proximal femur [1].

They may present clinically as localised pain and swelling, a pulsatile haematoma [4-6], compartment syndrome of the thigh [7] or compromise of the distal perfusion in case of peripheral occlusive disorders. Literature review revealed two cases of similar presentation in adults reported by Chang et al. [1]. In both the instances, there was triad of (1) thigh swelling, (2) bleeding from fasciotomy wound, and (3) anaemia with falling haemoglobin trend. Both the cases had fractures of the femur. In the present case, similar triad of features was observed, except that there was no associated fracture of the femur and it followed a surgical procedure of incision and drainage in a child.

Ultrasonography has been used to diagnose, define the cavity size and extent [6], but in the present case, we failed to make a diagnosis of the diagnosis of pseudoaneurysm on both the occasions. For cases that present with bleeding, angiography is an excellent diagnostic and therapeutic tool $[1,6]$. It can accurately delineate the site and size of the pseudoaneurysm, feeding vessels, and patency with adequacy of flow. This mode of investigation was most accurate in the present case also. We were able to diagnose not only the pseudoaneurysm but also the abnormal tortuous dilated feeding vessel.

MRI was also be used to diagnose the pseudoaneurysm and feeding vessel and rule out any muscular pathology (tear, contusion) leading to haemorrhage in the present case.

The presence of pseudoaneurysm formation may require immediate surgical or endovascular treatment. Most important factor affecting the treatment option is the origin of the pseudoaneurysm, which is from a major arterial branch or small deep muscular branch [2]. Pseudoaneurysm resulting from a major arterial branch can be treated endovascularly or surgically. Endovascular occlusion of pseudoaneurysms can be performed by percutaneous transcatheter embolisation, percutaneous endovascular covered stents and endovascular coiling. Ultrasound-guided compression can also be used. Surgical repair is indicated when endovascular occlusion fails or when facilities are not available $[1,2]$. Open surgical repair was performed in the present case, as our institute does not have the interventional radiologic facilities. 
Fig. 3 CT angiography:

a coronal and $\mathbf{b}$ axial sections showing abnormal, dilated and tortuous vessel (black arrow) and haemorrhage from incision site (white arrow)
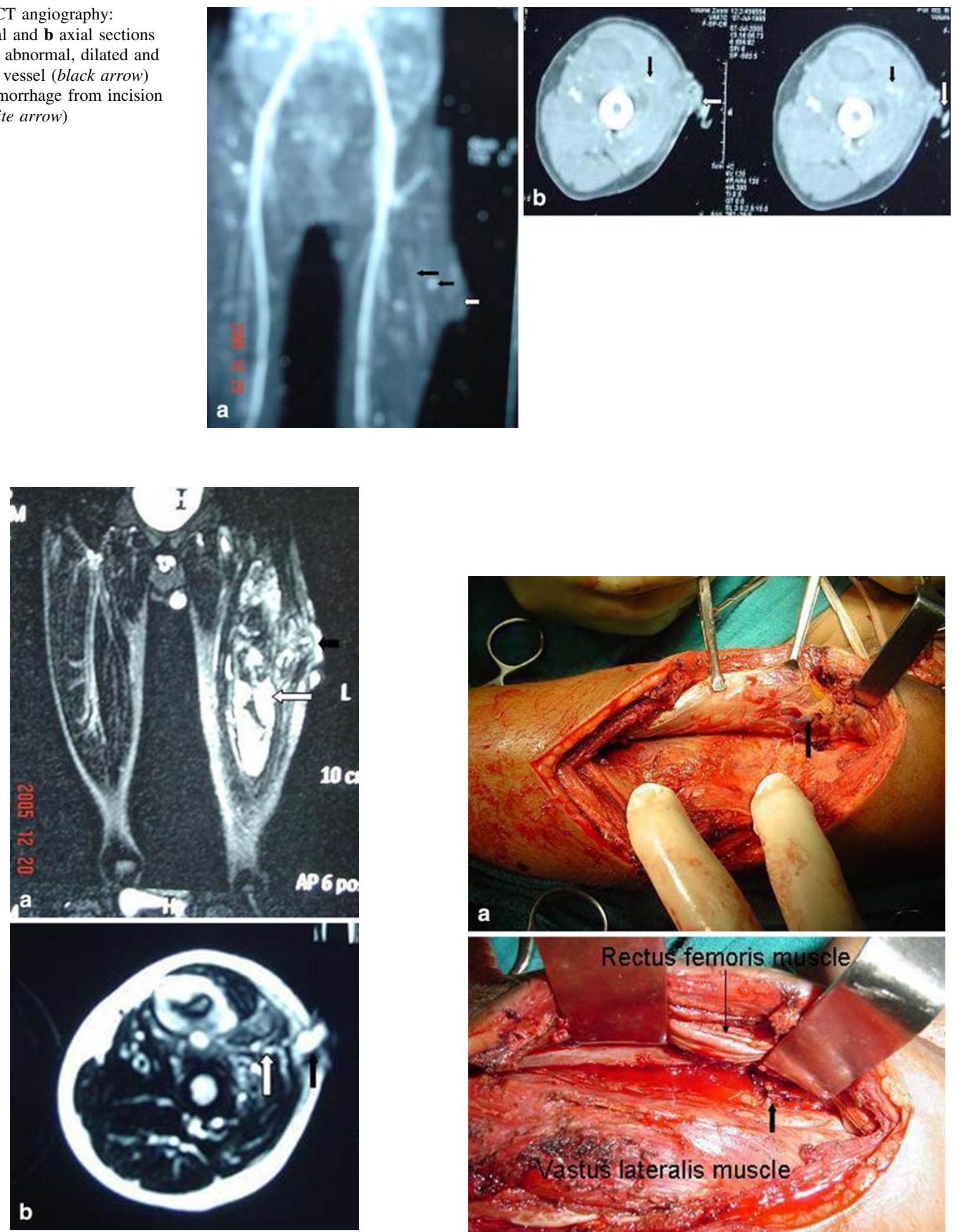

Fig. 4 MRI of the left thigh: a coronal section showing haematoma and fresh blood in-between the vasti muscles (pseudoaneurysm) (white arrow) and $\mathbf{b}$ axial sections showing abnormal, dilated and tortuous vessel (white arrow) and evidence of fresh haemorrhage from incision site (black arrow)
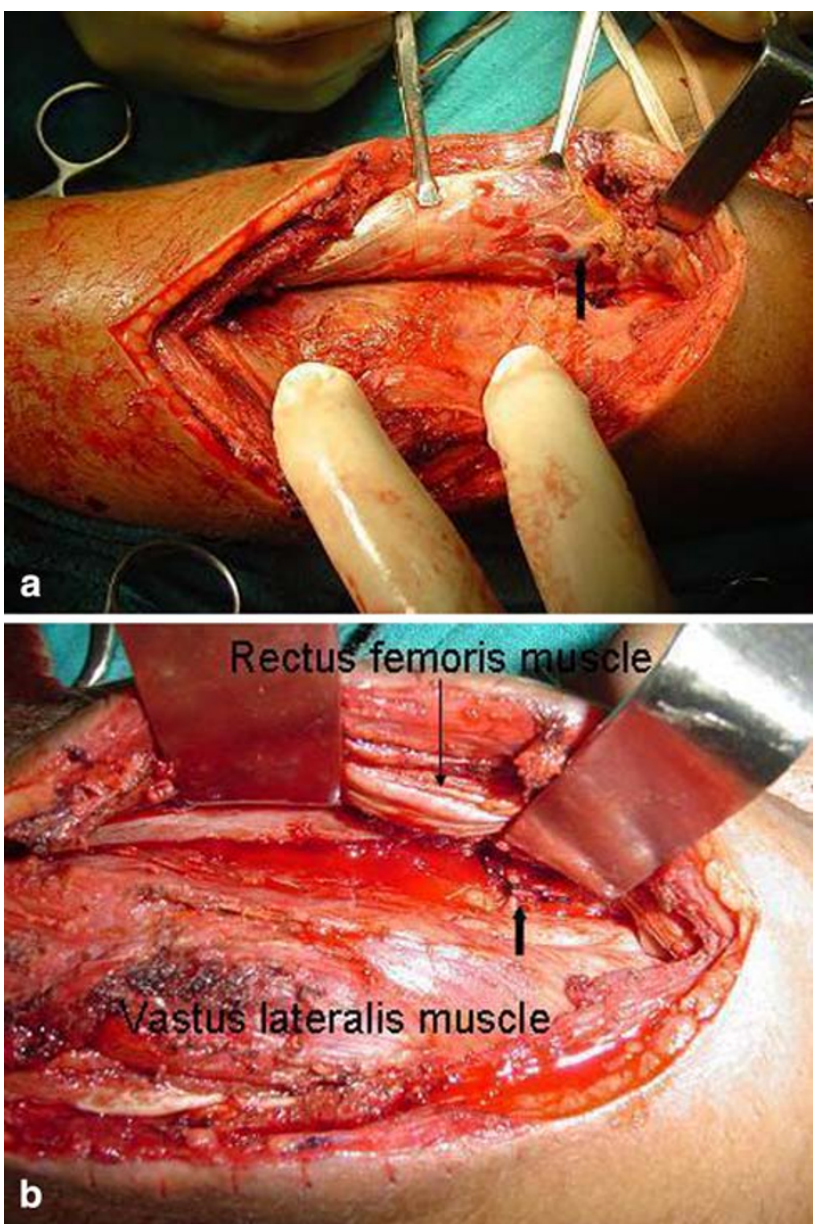

Fig. 5 Peroperative photographs showing a abnormally dilated and tortuous feeding vessel (arrow) and $\mathbf{b}$ feeding vessel ligated 


\section{Conclusions}

Pseudoaneurysm of profunda femoris artery following blunt trauma in children is rare. High index of suspicion is required for early diagnosis. A careful approach is required before any surgical intervention in a posttraumatic swelling. Pseudoaneurysm or neoangiogenesis should be considered in the differential diagnosis of soft tissue masses resulting from direct, blunt trauma even in children.

\section{References}

1. Chang KC, Yap EC, Lam KS, Low BY (2004) Profunda femoris artery pseudoaneurysm presenting with triad of thigh swelling, bleeding and anaemia. Ann Acad Med Singapore 33:267-269

2. Cantaasdemir M, Kantarei F, Mihmanli I, Numan F (2002) Embolisation of profunda femoris artery branch pseudoaneurysms with ethylene vinyl alcohol copolymer (onyx). J Vasc Interv Radiol 13:725-728
3. Kligman M, Mahrer A, Avi E, Roffman M (2002) Hypotension as a delayed complication of rupture of a branch of the superior gluteal artery, following buttock contusion: a case report. Injury 33:285-287

4. Hanna GB, Holdsworth RJ, McCollum PT (1994) Profunda femoris artery pseudoaneurysm following orthopaedic procedures. Injury 25:477-479

5. O'Donoghue D, Muddu BN, Woodyer AB, Kumar R (1999) False aneurysm of profunda femoris artery due to malunion of a hip fracture. Injury 25:681-682

6. Jargiello T, Zubilewicz M, Szaner M, Pietura R, SzcerboTrozanwska M (1998) Pulsating mass after accidental artery trauma: diagnosis with duplex ultrasound and the role of angiography. Vascular 27:111-117

7. Karkas CD, Hughes R, Parsad V, D'Souza S (1999) Thigh compartment syndrome as a result of false aneurysm of the profunda femoris artery complicating fixation of intertrochanteric fracture. Injury 47:393-397

8. Vaidyalingasharma R, Joshi YV, Sanger R (2008) Pseudoaneurys of medial branch of the profunda femoris artery following dynamic hip screw fixation of proximal fracture: a case report. Eur J Orthop Surg Traumatol 18:59-61

9. Annenberg AJ, vaccaro PS, Zuelzer WA (1990) Traumatic pseudoaneurysm in a wrestler. Ann Vasc Surg 4(1):69-71 